\title{
Julie Delporte : dévoilement par le biais du texte et de l'image
}

\section{Tamara EL-HOSS, Université Brock}

L'art de Julie Deporte est plein de couleur, d'émotions et d'énergie. Il est, malgré le contenu souvent sérieux, rafraîchissant ; l'opposition entre le texte et l'image est ce qui lui donne sa force ainsi que son charme.

Son journal (2013) met en scène une période difficile post-rupture par laquelle elle passe entre février 2011 et octobre 2012 et, à première vue, semble servir de thérapie à l'auteure/l'artiste qui n'hésite ni à décrire ni à illustrer de sombres moments vécus qui frôlent parfois la dépression. Le texte, souvent composé de pensées et d'impressions brèves mélangées aux sentiments forts et profonds qui cherchent à faire surface, paraît parfois décousu, sans but précis, mais a bel et bien un dénominateur en commun : la reconstruction de soi après une rupture difficile, bouleversante. Dessiner a chez elle une importance primordiale, c'est grâce à ses dessins, donc son art, à ses amis et à ses lectures, qu'elle réussira à se (re)connaître et à sortir de cette longue et pénible période. Les images en couleur qui accompagnent le texte, sont légères et vives, voire « vivantes »; elles paraissent parfois naïves, une naïveté peut-être voulue qui s'oppose au contenu du texte. Le «je autobiographique » (narratif ainsi que dessiné) s'expose, se dévoile : «Private things, to me, are about taboo, feeling smothered, secrets you can't talk about, to keep up appearances despite a truth that always made me feel relieved. It's also about shame. (I recognize all this while reading Annie Ernaux.) » (n.p.). C'est le contraste entre les illustrations et la narration qui rend ce journal, ainsi que d'autres pages que l'artiste a mises sur son blog, captivants.

Le personnage du loup, qui pourrait être symboliquement «le grand méchant loup », paraît ici et là dans le journal, furtivement. Il est, cependant, repris en plus de détail dans quelques pages disponibles sur le blog Le dernier kilomètre (http://ledernierkilometre.blogspot.ca/) de l'artiste/l'auteure, notamment dans «On ne parle pas » et «My desire and the winter», créées en 2011 - en pleine rupture, donc. La présence du loup dans ces dernières images est plus développée, plus pointue, il représenterait une figure masculine sexualisée, le désir sexuel de Delporte peut-être. 
C'est ici, dans ces deux pages ouvertement accessibles en ligne, donc publiques, que l'auteure/l'artiste se dévoile le plus. On a quasiment l'impression que la page qu'elle crée, fait partie de son corps, que ses désirs charnels prennent le dessus, et que le lien entre son art et son corps en est un qui est très puissant. L'acte sexuel évoqué sur la page révèle, selon Delporte, "la limite entre le sacré et le profane »: puissante image de transgression. À travers le loup elle fait allusion, bien sûr, au conte du petit chaperon rouge ; il n'est toutefois pas très clair quelle version elle préfère, celle de Perrault ou celle des frères Grimm. En d'autres mots : sera-t-elle dévorée par son propre désir ou non ?

Que ce soit dans son Journal ou dans «On ne parle pas » et « My desire and the winter », le travail de Julie Delporte est authentique. L'auteure/l'artiste ne se cache pas derrière son art ; bien au contraire, elle y expose son « je autobiographique » avec toutes ses anxiétés, imperfections et vulnérabilités. $\mathrm{Si}$ « on ne parle pas » des tabous, « de ces choses-là » en public, comme par exemple s'il y a des «pilules pour vous faire aimer les blow job ? », Delporte dessine «ces choses-là », les écrit et les publie - que ce soit dans un livre ou sur son blog. Elle élimine, ce faisant, toute frontière qui existerait entre ce qui devrait être public et ce qui devrait être privé mais qui, grâce à son art, n'est plus ni l'un ni l'autre (mais pourrait être une combinaison des deux).

L'art de Julie Delporte est sincère, attachant. Elle y aborde des sujets souvent « interdits » dans notre société, se dévoile graduellement devant nous sur la page. Au fur et à mesure qu'elle se « découvre », elle transgresse la frontière entre les sphères publique et privée, se libérant ainsi des contraintes sociétales, familiales et culturelles qui lui ont été imposées depuis l'enfance. Elle s'assume en couleur et en public, courageuse. 